\title{
BRD4 Inhibitor PLX2853
}

National Cancer Institute

\section{Source}

National Cancer Institute. BRD4 Inhibitor PLX2853. NCI Thesaurus. Code C146825.

An orally bioavailable inhibitor of the bromodomain-containing protein 4 (BRD4), with potential antineoplastic activity. Upon oral administration, the BRD4 inhibitor PLX2853 binds to the acetylated lysine recognition motifs in the bromodomains of the BRD4 protein, thereby preventing the binding of BRD4 to acetylated lysines on histones. This disrupts chromatin remodeling and dyregulates gene expression. This may lead to the downregulation of the expression of certain growth-promoting genes, which may induce apoptosis and inhibit the proliferation of BRD4-overexpressing tumor cells. BRD4, a member of the human bromodomain and extra-terminal (BET) family of proteins, is a transcriptional regulator that is overexpressed in certain tumor cells and plays an important role in cellular proliferation. 